\title{
Effects of a spoilage yeast from silage on in vitro ruminal fermentation
}

\author{
M. C. Santos, ${ }^{*}$ A. L. Lock, † G. D. Mechor, $\ddagger$ and L. Kung Jr. ${ }^{* 1}$ \\ *Department of Animal and Food Sciences, University of Delaware, Newark 19716 \\ †Department of Animal Science, Michigan State University, East Lansing 48824-1225 \\ ‡Elanco Animal Health, Orchard Park, NY 14127-2074
}

\section{ABSTRACT}

Feeding silages with high concentrations of yeasts from aerobic spoilage is often implicated as a cause of poor animal performance on dairies. Our objective was to determine if a commonly found spoilage yeast, isolated from silage, had the potential to alter in vitro ruminal fermentations. A single colony of Issatchenkia orientalis, isolated from high-moisture corn, was grown in selective medium. The yeast culture was purified and added to in vitro culture tubes containing a total mixed ration ( $43 \%$ concentrate, $43 \%$ corn silage, $11 \%$ alfalfa haylage, and $3 \%$ alfalfa hay on a dry matter basis), buffer, and ruminal fluid to achieve added theoretical final concentrations of 0 (CTR), 4.40 (low yeast; LY), 6.40 (medium yeast; MY), and 8.40 (high yeast; HY) $\log _{10} \mathrm{cfu}$ of yeast $/ \mathrm{mL}$ of in vitro fluid. Seven separate tubes were prepared for each treatment and each time point and incubated for 12 and $24 \mathrm{~h}$ at $39^{\circ} \mathrm{C}$. At the end of the incubation period, samples were analyzed for $\mathrm{pH}$, yeast number, neutral detergent fiber (NDF) digestibility, volatile fatty acids (VFA), and fatty acids (FA). We found that total viable yeast counts decreased for all treatments in in vitro incubations but were still relatively high (5.3 $\log _{10}$ cfu of yeasts/ $\mathrm{mL}$ ) for $\mathrm{HY}$ after $24 \mathrm{~h}$ of incubation. Addition of $\mathrm{HY}$ resulted in a lower $\mathrm{pH}$ and higher concentration of total VFA in culture fluid compared with other treatments. Moreover, additions of MY and HY decreased in vitro NDF digestibility compared with CTR, and the effect was greatest for HY. Overall, the biohydrogenation of dietary unsaturated FA was not altered by addition of I. orientalis and decreased over time with an increase in the accumulation of saturated FA, especially palmitic and stearic acids. We conclude that addition of I. orientalis, especially at high levels, has the potential to reduce in vitro NDF digestion and alter other aspects of ruminal fermentations.

Key words: corn silage, fiber digestibility, Issatchenkia orientalis, milk fat depression

Received July 30, 2014.

Accepted December 3, 2014.

${ }^{1}$ Corresponding author: lksilage@udel.edu

\section{INTRODUCTION}

When silage is exposed to air, lactate-assimilating yeasts from Candida, Pichia, Hansenula, and Endomycopsis (Moon and Ely, 1979; Jonsson and Pahlow, 1984; McDonald et al., 1991) are often the primary initiators of aerobic spoilage (Jonsson and Pahlow, 1984). The degradation of lactic acid results in an increase in silage $\mathrm{pH}$ to a level that allows opportunistic bacteria (e.g., bacilli) and molds (e.g., Aspergillus, Fusarium, and Penicillium) to grow and further reduce silage quality (McDonald et al., 1991).

Silages that have been exposed to air can be usually characterized into 2 general categories: those that are actively spoiling (high numbers of yeasts $\geq 5.5$ to 6 $\log _{10} \mathrm{cfu} / \mathrm{g}$, temperatures $>36-38^{\circ} \mathrm{C}$, and low concentrations of fermentation acids, mainly lactic and acetic acids) and those that have spoiled and been stored for prolonged periods (e.g., the top portions of silages in bunker and pile silos). In the latter, it is not uncommon for the number of yeasts to be low or zero; Vissers et al. (2007) stated that silages with signs of aerobic deterioration are associated with high concentrations of spores of butyric acid bacteria (above $5 \mathrm{log} / \mathrm{g}$ ). Both spoiled and spoiling silages pose threats to animals because they may contain undesirable microorganisms (e.g., Listeria monocytogenes and Clostridium botulinum) and mycotoxins and they may be of generally lower nutritive value due to the destruction of nutrients during spoiling (McDonald et al., 1991). The numbers of yeasts in silages vary greatly and can be affected by many different management factors, including packing density, silage DM, fermentation end-products, and the type of plastic used to seal silos (Borreani and Tabacco, 2014).

Anecdotal reports from the field suggest that problems with low intake or low milk fat tests are often reported when cows have consumed silages with high numbers of yeasts (G. D. Mechor and L. Kung Jr., personal observations). Surprisingly, only a small number of studies have evaluated the effects of feeding spoiled or spoiling silages to ruminants. Whitlock et al. (2000) reported that feeding spoiled corn silage from the surface of a bunker silo depressed nutrient digestibility and 
DM intake of steers. The spoiled silage probably had this effect because its overall nutritive value was low, with levels of NDF and ADF being 14.8 and 32.5\% higher than the levels found in the nonspoiled portion of the silages, respectively. Hoffman and Ocker (1997) fed a TMR containing fresh or aerobically deteriorating high-moisture corn. Cows that were fed the TMR containing the aerobically spoiling high-moisture corn produced $3.2 \mathrm{~kg}$ less milk/cow per day compared with cows fed fresh silage, although DM intake was unaffected. Gerlach et al. (2013) fed spoiling silage to goats and reported negative correlations between ethyl lactate and ethanol with DMI but the strongest negative relationship with intake was from silage temperature (difference from ambient). Because spoiled silages often have high numbers of yeasts, the role that yeasts play in negatively affecting animal performance has been questioned. Ward (2011) reported that in 2010-2011, approximately 15, 15, and 9\% of corn silage samples tested for yeasts contained approximately 7, 8, and 9 $\log _{10}$ cfu of yeasts/g of wet silage, respectively. Similarly, studies conducted by Dolci et al. (2011) and Borreani et al. (2013) reported total numbers of yeasts in silages as high as $8 \log _{10} \mathrm{cfu} / \mathrm{g}$. Thus, the objective of this experiment was to determine whether high numbers of a spoilage yeast isolated from silage could adversely affect ruminal in vitro fermentations.

\section{MATERIALS AND METHODS}

\section{Experimental Design}

Issatchenkia orientalis (formerly known as Candida krusei), was identified by DNA sequencing and physiological substrate profiling and is a predominant species of yeasts in high moisture corn and corn silage (Santos et al., 2011). The yeast was grown in sterile Erlenmeyer flasks containing autoclaved Sabouraud dextrose broth (Becton Dickinson, Sparks, MD) and incubated at $32^{\circ} \mathrm{C}$ in a shaker box (Thermo Scientific, Waltham, MA) at $120 \mathrm{rpm}$. When the optical density of the culture at 600 $\mathrm{nm}$ was constant (stationary phase), the cells were harvested by centrifugation at $1,077 \times g$ for $10 \mathrm{~min}$ at $5^{\circ} \mathrm{C}$. After centrifugation, the cells were washed using sterile Ringers solution and concentrated by centrifuging an additional 2 times. A pure culture of $I$. orientalis was obtained by resuspending the pellet in sterile Ringer's solution. The concentration of $I$. orientalis in the pure culture was determined by plating 1-mL aliquots of 10fold serial dilutions on yeast and mold count Petrifilm (3M Products, St. Paul, MN).

In vitro ruminal incubations were performed according to the procedure of Goering and Van Soest (1970) with modifications. The modifications included incuba- tions in $50-\mathrm{mL}$ tubes with $0.3 \mathrm{~g}$ of a TMR mixed with $24 \mathrm{~mL}$ of mineral and buffer plus $6 \mathrm{~mL}$ of strained ruminal fluid. The TMR consisted of $43 \%$ concentrate, $43 \%$ corn silage, $11 \%$ alfalfa haylage, and $3 \%$ alfalfa hay on a DM basis and was balanced according to the NRC (2001) to meet the requirements of lactating dairy cows (average $72 \mathrm{DIM}, 48 \mathrm{~kg}$ of milk/d, $28 \mathrm{~kg}$ of DMI/d, and $716 \mathrm{~kg}$ of $\mathrm{BW}$ ). The ingredient composition and the nutritive value of the whole TMR are shown in Table 1. The TMR sample had been dried for $48 \mathrm{~h}$ at $60^{\circ} \mathrm{C}$ in a forced-air oven and ground through a $1-\mathrm{mm}$ screen using a Cyclone Sample Mill (Udy Corp., Fort Collins, CO). Ruminal fluid was collected after morning feedings from 2 cannulated lactating Holstein cows fed the same TMR once daily and ad libitum. Ruminal fluid was pooled, strained through a double layer of cheesecloth while being gassed continuously with $\mathrm{CO}_{2}$, and used immediately to inoculate tubes.

Yeasts were added to culture tubes to achieve a theoretical concentration of 0 (CTR), 4.4 (low yeast; LY), 6.4 (medium yeast; $\mathbf{M Y}$ ), and 8.4 (high yeast; $\mathbf{H Y}$ ) $\log _{10}$ cfu of added I. orientalis $/ \mathrm{mL}$ of total in vitro fluid. The LY dose was established based on a calculation of a cow with a rumen liquid volume of $126 \mathrm{~L}$ consuming $30 \mathrm{~kg}$ of as-fed corn silage containing $5 \log _{10}$ cfu of yeasts/g. The $4.4 \log _{10} \mathrm{cfu} / \mathrm{mL}$ dose was obtained by multiplying the intake of corn silage ( $30 \mathrm{~kg}$ of fresh silage) by the concentration of yeasts $\left(5 \log _{10} \mathrm{cfu} / \mathrm{g}\right.$ of fresh sample) and dividing this result by the rumen volume $(126 \mathrm{~L})$. The MY and HY doses were calculated similarly but with the assumption that the former contained $7 \log _{10}$

Table 1. Ingredient composition and nutritive value of the whole TMR used in the in vitro fermentation

\begin{tabular}{lc}
\hline Composition & Value \\
\hline Ingredient (\% of DM) & \\
Corn silage & 43.0 \\
Alfalfa haylage & 11.2 \\
Alfalfa hay & 2.7 \\
Concentrate & 43.1 \\
Nutritive value & \\
DM (\%) & 50.8 \\
CP (\% of DM) & 16.0 \\
Soluble protein (\% of CP) & 29.8 \\
NE $($ Mcal/kg of DM) & 1.63 \\
ADF (\% of DM) & 21.5 \\
NDF (\% of DM) & 33.8 \\
Ash (\% of DM) & 6.5 \\
Starch $\%$ of DM) & 28.0 \\
\hline
\end{tabular}

${ }^{1}$ Concentrate composition was (DM basis) $26.2 \%$ corn hominy, $13.9 \%$ canola meal, $12.4 \%$ soybean meal, $11.8 \%$ ground corn grain, $11.3 \%$ turbo meal (extruded expelled soybean meal product), $7.0 \%$ dried citrus pulp, $3.3 \%$ ground soybean hulls, $3.2 \%$ corn distillers grains, $2.1 \%$ calcium carbonate, $2.0 \%$ blood meal, $1.6 \%$ sodium bicarbonate, $1.3 \%$ molasses cane, $0.9 \%$ salt, $0.9 \%$ saturated fat source of palmitic acid, $0.7 \%$ mineral and vitamin premix, $0.5 \%$ urea, $0.4 \%$ Rumensin (Elanco Animal Health, Greenfield, IN), $0.2 \%$ magnesium oxide, $0.2 \%$ encapsulated source of methionine and $0.1 \%$ calcium sulfate dehydrate. 
cfu of yeasts/g and the latter contained $9 \log _{10}$ cfu yeasts/g. Three runs for $12 \mathrm{~h}$ and 4 runs for $24 \mathrm{~h}$ were conducted. On each day, 7 tubes were prepared for each treatment and each time point. Three tubes were used for the determination of number of yeasts, VFA, and $\mathrm{pH}$. The remaining 4 tubes were used for determination of NDF digestibility (NDF-D). The concentration of FA in culture fluid was analyzed for only 1 of the 4 incubations. The concentration of yeasts was determined by plating 1-mL serial dilutions on yeast and mold count Petrifilm (3M Products). Another 1-mL sample was collected for determination of VFA by HPLC (Muck and Dickerson, 1988). The HPLC system consisted of a Shimadzu system controller (CBM-20A), pump (LC-20AT), and refractive index detector (RID-10A; Shimadzu Corp., Kyoto, Japan) with a Bio-Rad Aminex HPX-87H ion exchange column $(300 \mathrm{~mm} \times 7.8 \mathrm{~mm}$ i.d.; Bio-Rad Laboratories, Hercules, CA) heated to $35^{\circ} \mathrm{C}$, and with a mobile phase composed of $0.015 \mathrm{~N} \mathrm{H}_{2} \mathrm{SO}_{4}$ plus 0.25 $\mathrm{m} M$ EDTA at $0.6 \mathrm{~mL} / \mathrm{min}$. The $\mathrm{pH}$ of in vitro solution was determined using a Corning $\mathrm{pH}$ meter (model no. 220, Corning Science Products, Corning, NY). For the determination of NDF-D, in vitro incubations were stopped by immersing the tubes in an ice bath and by acidifying them with $900 \mu \mathrm{L}$ of $6 N \mathrm{HCl}$. Acidified tubes were immediately removed from the ice bath and stored at $-20^{\circ} \mathrm{C}$ before NDF analyses. The NDF (Van Soest et al., 1991) concentration was determined before and after ruminal incubations using a heat-stable $\alpha$-amylase and sodium sulfite and with the modification that Whatman 934-AH glass micro-fiber filters with $1.5-\mu \mathrm{m}$ particle retention (Whatman, Florham Park, NJ) were used in place of fritted glass crucibles.

Frozen tubes from the in vitro incubation and from the pure culture of $I$. orientalis were freeze-dried and FAME prepared using an in situ extraction-2-step methylation procedure according to Jenkins (2010). The FAME were quantified using a GC-2010 Plus gas chromatograph (Shimadzu Corp.) equipped with a split injector (1:100 split ratio) and a flame-ionization detector using a CP-Sil 88 WCOT fused-silica column $(100 \mathrm{~m} \times$ $0.25 \mathrm{~mm}$ i.d. $\times 0.2 \mu \mathrm{m}$ film thickness; Varian Inc., Lake Forest, CA). Fatty acid methyl esters were identified by comparison of retention times with known FAME standards (Supelco 37 component fatty acid methyl ester mix, cis/trans fatty acid methyl esters mix, BAME mix, and PUFA No. 3 mix from Supelco Inc., Bellefonte, PA; GLC reference standard 463 and CLA mixture \#UC-59 M from Nu-Chek Prep., Elysian, MN).

\section{Statistical Analysis}

All data were analyzed as a completely randomized design using the PROC MIXED procedure of SAS (SAS
Institute, 1999), with day of incubation considered a random effect. Due to a lack of interaction between treatment $\times$ time $(P=0.20)$ for NDF-D, treatment averages within each time point were shown separately, whereas for the other parameters a treatment $\times$ time interaction was shown. Data were reported as least squares means, and mean separation was tested using the PDIFF option in SAS. Significant differences between treatments were declared at $P \leq 0.05$ and trends were noted at $P \geq 0.05$ to $P \leq 10$.

\section{RESULTS AND DISCUSSION}

Lactate-assimilating yeasts are often primarily responsible for the initiation of aerobic deterioration of silages and their numbers can be high in silages fed to cows (Ward, 2011). However, to our knowledge, no studies have evaluated the direct effects of spoilage yeasts on ruminal fermentation. We choose to evaluate I. orientalis (C. krusei) because it is a lactate-utilizing yeast commonly found in silages (Middelhoven, 1998). For example, it represented $14.1 \%$ of identified yeasts in 21 samples of corn silage and high-moisture corn samples (Santos et al., 2011). The $\mathrm{pH}$ and numbers of yeasts in culture fluid during in vitro incubations are presented in Table 2. Overall, culture $\mathrm{pH}$ declined from about 6.82 at time 0 to 6.40 and 6.37 at 12 and $24 \mathrm{~h}$, respectively. This decrease in $\mathrm{pH}$ was expected because the accumulation of acids from fermentation increases acidity in a closed fermentation system. The final $\mathrm{pH}$ of the cultures remained within a range of $\mathrm{pH}$ (6.0 to 7.0) required for optimal rumen fibrolytic activity, as growth of fibrolytic bacteria is known to be inhibited at $\mathrm{pH}<6.0$ (Weimer, 1996).

The measured numbers of total viable yeasts in culture fluid were close to the expected theoretical numbers for LY (4.02 vs. $4.40 \log _{10} \mathrm{cfu} / \mathrm{mL}$ ), MY (5.92 vs. $6.40)$, and HY (8.18 vs. 8.40) treatments. An interaction between time of incubation and numbers of yeasts was found: numbers of yeasts declined more markedly for CTR and HY between 12 and $24 \mathrm{~h}$ than they did for LY and MY. The reason for this finding is unknown. The concentrations of yeasts in culture fluid used in our study were within practically possible ranges, considering that data from Ward (2011) reported corn silages with numbers of yeasts ranging from 3 to $\geq 9 \log _{10} \mathrm{cfu} / \mathrm{g}$ of silage. Culture fluid in CTR contained $2.42 \log _{10}$ cfu of yeasts $/ \mathrm{mL}$, indicating that a low level of yeasts was naturally present in the ruminal fluid from the donor animals. This finding was not surprising as the donor animals were fed a diet that contained corn and alfalfa silages. Lund (1974) examined the yeast contents in 49 samples of rumen fluid collected from 12 cows at varying intervals when receiving different diets. He found 


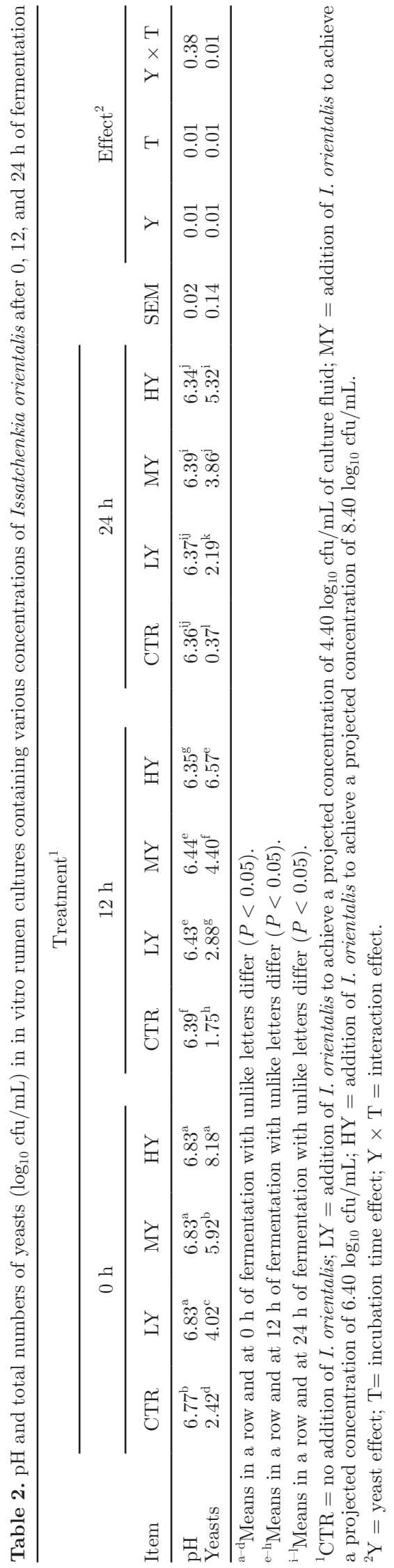

that only small numbers of yeasts were detected in rumen fluid and that the numbers varied considerably in samples taken at different times from the same animal. In that report, the number of yeasts in the rumen fluid collected from animals fed diets that did not contain silage rarely exceeded $2 \log _{10} \mathrm{cfu}$ of yeasts $/ \mathrm{mL}$, whereas samples from animals fed silages contained up to 3.5 $\log _{10}$ cfu of yeasts/mL of ruminal fluid. In our study, numbers of total yeasts in ruminal fluid declined over time of incubation but were still $5.32 \log _{10} \mathrm{cfu} / \mathrm{mL}$ after $24 \mathrm{~h}$ for HY. The fact that numbers of yeasts were still high after $24 \mathrm{~h}$ of incubation is supported by the data of Kung et al. (1997). They added a direct-fed microbial strain of Saccharomyces cerevisiae to sterile ruminal fluid at a rate of approximately $6.5 \log _{10} \mathrm{cfu} /$ $\mathrm{mL}$ of ruminal fluid and reported that this organism was able to maintain viable counts through $24 \mathrm{~h}$ of incubation, although some cell death took place by 48 $\mathrm{h}$, showing a final concentration of approximately 4.5 $\log _{10} \mathrm{cfu} / \mathrm{mL}$ of ruminal fluid.

Figure 1 shows the effect of treatments on in vitro NDF-D at $12 \mathrm{~h}$. We found that treatment with HY reduced NDF-D from $43.9 \%$ in control incubations to $33.9 \%(P<0.05)$, a reduction of $23 \%$. For MY, the reduction was $7.3 \%$ ( 40.7 vs. $43.9 \%$ in the control; $P$ $<0.05)$ but for LY, fiber digestibility was not altered (42.1 vs. $43.9 \%$ in the control). The results for NDF-D after $24 \mathrm{~h}$ of incubation showed a similar trend. These findings suggest that when cows are fed silages with high populations of I. orientalis $\left(\geq 7.0 \log _{10} \mathrm{cfu} / \mathrm{g}\right.$ of forage), the potential exists for these organisms to disrupt ruminal fiber digestion. Cultures with the HY level of $I$. orientalis were consistently lower in $\mathrm{pH}$ compared with CTR, but these differences were small and do not fully explain the differences in NDF-D among these treatments.

Analysis of VFA in the in vitro incubations is shown in Table 3. Total concentrations of VFA, acetate, and propionate for the LY and MY levels were very similar to those in the CTR treatment, except for acetate at $24 \mathrm{~h}$ for the LY treatment. In contrast, the HY level of $I$. orientalis increased total concentration of VFA and the individual concentrations of acetate and propionate compared with the other treatments after 12or 24-h incubations. Specifically, the concentrations of total VFA, acetate, and propionate were 106.2, 57.0, and $28.6 \mathrm{~m} M$ for the HY dose, compared with 97.8, 53.4 and $25.2 \mathrm{mM}$, respectively, for the CTR dose, at time $24 \mathrm{~h}$. The higher concentration of total VFA and individual acids was not expected for the HY level due to a reduction in NDF-D and was probably the result of increased digestion of nonfiber components of the ration by many rumen bacteria, such as Fibrobacter succinogenes, Butyrivibrio fibrisolvens, Prevotella ru- 

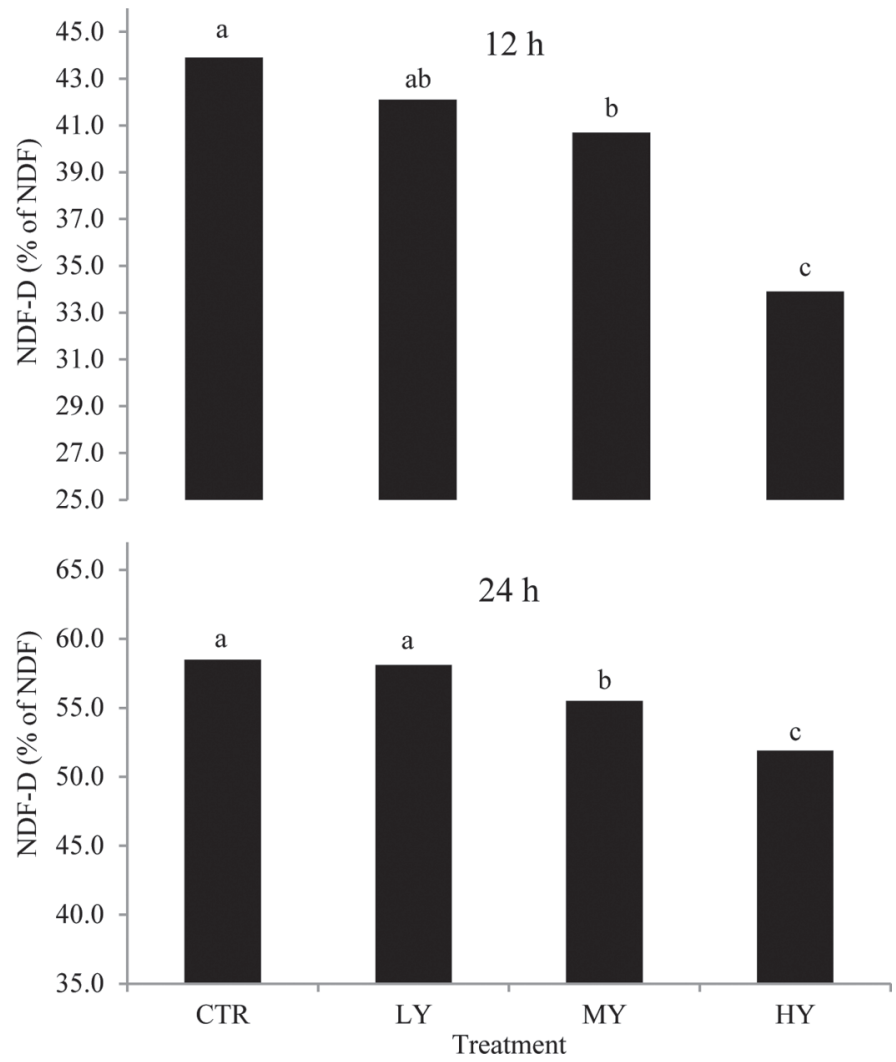

Figure 1. The in vitro digestibility of NDF (NDF-D; \% of NDF) from a TMR incubated with varying amounts of Issatchenkia orientalis and incubated for 12 (average of 3 incubations) and $24 \mathrm{~h}$ (average of 4 incubations). CTR $=$ no addition of $I$. orientalis; $\mathrm{LY}=$ addition of $I$. orientalis to achieve a projected concentration of $4.40 \log _{10} \mathrm{cfu} /$ $\mathrm{mL}$ of culture medium; MY = addition of $I$. orientalis to achieve a projected concentration of $6.40 \log _{10} \mathrm{cfu} / \mathrm{mL} ; \mathrm{HY}=$ addition of $I$. orientalis to achieve a projected concentration of $8.40 \log _{10} \mathrm{cfu} / \mathrm{mL}$. Bars with different letters differ $(P<0.05)$. SE $=1.7$ and 2.3 for 12 and $24 \mathrm{~h}$, respectively.

minicola, and Prevotella bryantii, that are capable of utilizing different energy sources (i.e., structural and nonstructural carbohydrates; Belanche et al., 2012). For the concentration of butyrate, no treatment effects were evident, whereas for the acetate:propionate ratio, the $\mathrm{HY}$ level at $24 \mathrm{~h}$ showed a greater proportion of propionate, although the actual differences among treatments were very small. Tripathi et al. (2008) evaluated ruminal fermentation parameters of lambs supplemented with live yeast cultures of Kluyveromyces marxianus, S. cerevisiae, Saccharomyces uvarum, or a mixed culture (all 3 cultures in 1:1:1 ratio). They reported a trend of reduction in total VFA concentration in rumen fluid when lambs were supplemented with S. cerevisiae, S. uvarum, or a mixed culture. Chung et al. (2011) compared ruminal fermentation parameters of dairy cows fed diets containing a commercial strain of $S$. cerevisiae widely used in dairy production with a novel strain that is not used commercially and with a control diet. The authors found that the concentration of total VFA in the rumen fluid was similar among treatments; however, the novel strain decreased the proportion of acetate compared with the commercial strain and increased the proportion of propionate compared with the control or the commercial strain. Chung et al. (2011) also reported that strains of S. cerevisiae differed in their effects on ruminal fermentation and they noted the ability of one of the strains to modify the rumen toward a more acidic environment. In contrast, Desnoyers et al. (2009) completed a meta-analysis of the influence of $S$. cerevisiae on ruminal parameters and concluded that addition of this microorganism increased rumen $\mathrm{pH}$ and rumen VFA concentration. The variation in the results found in the literature and in our study may be explained by the species of yeasts that were studied, levels of inoculation, and experimental conditions (i.e., in vitro vs. in vivo).

The concentration of total FA of $I$. orientalis was $1.67 \%$ and the FA composition showed that C18:1 cis-9 (43.3\%), SFA (22.9\%), mainly C16:0 (19.7\%), C18:2 cis-9,cis-12 (14.3\%), and C16:1 cis-9 (13.0\%) were the major FA found in this yeast (data not shown). With the exception of $\mathrm{C} 16: 1$ cis-9, all of these FA plus C18:0 were found in high percentages in the in vitro cultures at time 0 compared with C18:1 trans (Table 4). Timke et al. (2008) analyzed the FA composition of yeasts isolated from process surfaces of 2 breweries and they found that $\mathrm{C} 16: 0, \mathrm{C} 18: 2$ cis-9,cis-12, and $\mathrm{C} 16: 1$ cis-9 were the major FA present in one strain identified as I. orientalis, at concentrations of 9.8, 17.7, and $6.7 \%$ of total FA, respectively. For the in vitro culture in our study, the major unsaturated FA at time 0 were influenced by the composition of the TMR, which was predominantly corn silage ( $43 \%$ of the TMR) and concentrate that was formulated to have corn hominy, canola meal, soybean meal, and ground corn grain as the major components. Furthermore, the presence of SFA at time 0 could be attributed to biohydrogenation that occurred in the cows before the rumen fluid was sampled.

Table 4 shows that a yeast $\times$ incubation time interaction was observed for all FA, except for $\Sigma$ C18:1 trans, C18:1 trans-10, $\Sigma$ SFA, and C18:0. The proportions of PUFA and MUFA decreased over time, with concomitant increases in the proportion of C18:1 trans and SFA, particularly C18:0 (Table 4) and C16:0 (data not shown). These findings suggested that normal biohydrogenation pathways were operative in our in vitro system. Biohydrogenation of unsaturated FA is a characteristic process that occurs in the rumen to alleviate the toxic effects that double bonds exert on ruminal bacteria (Maia et al., 2007). Individual analysis of the FA showed that the proportion of $\mathrm{C} 18: 2$ cis-9, cis- 12 
Table 3. Volatile fatty acid concentrations $(\mathrm{mM})$ of in vitro rumen cultures containing various concentrations of Issatchenkia orientalis after 0 , 12 , and $24 \mathrm{~h}$ of fermentation

Treatment $^{1}$

$12 \mathrm{~h}$

$24 \mathrm{~h}$

\begin{tabular}{cccc}
\hline CTR & LY & MY & HY \\
$81.3^{\mathrm{b}}$ & $80.7^{\mathrm{b}}$ & $82.5^{\mathrm{b}}$ & $91.2^{\mathrm{a}}$ \\
$43.7^{\mathrm{bc}}$ & $42.8^{\mathrm{c}}$ & $44.7^{\mathrm{b}}$ & $48.7^{\mathrm{a}}$ \\
$19.0^{\mathrm{b}}$ & $18.3^{\mathrm{b}}$ & $19.5^{\mathrm{b}}$ & $22.3^{\mathrm{a}}$ \\
11.1 & 10.5 & 11.0 & 11.5 \\
2.3 & 2.3 & 2.3 & 2.2
\end{tabular}

${ }^{\mathrm{a}-\mathrm{c}}$ Means in a row and at $12 \mathrm{~h}$ of fermentation with unlike letters $\operatorname{differ}(P<0.05)$.

${ }^{\mathrm{d}-\mathrm{f}}$ Means in a row and at $24 \mathrm{~h}$ of fermentation with unlike letters differ $(P<0.05)$.

${ }^{1} \mathrm{CTR}=$ no addition of $I$. orientalis $; \mathrm{LY}=$ addition of I. orientalis to achieve a projected concentration of $4.40 \log 10 \mathrm{cfu} / \mathrm{mL} ; \mathrm{MY}=$ addition of $I$. orientalis to achieve a projected concentration of $6.40 \log _{10} \mathrm{cfu} / \mathrm{mL} ; \mathrm{HY}=$ addition of $I$. orientalis to achieve a projected concentration of $8.40 \log _{10} \mathrm{cfu} / \mathrm{mL}$.

${ }^{2} \mathrm{Y}=$ yeast effect; $\mathrm{T}=$ incubation time effect; $\mathrm{Y} \times \mathrm{T}=$ interaction effect.

Table 4. Fatty acid composition ( $\mathrm{g} / 100 \mathrm{~g}$ of total FA) of in vitro rumen cultures containing various concentrations of Issatchenkia orientalis after 0 , 12 , and $24 \mathrm{~h}$ of fermentation

\begin{tabular}{|c|c|c|c|c|c|c|c|c|c|c|c|c|c|c|c|c|}
\hline \multirow[b]{3}{*}{ FA } & \multicolumn{12}{|c|}{ Treatment $^{1}$} & \multirow[b]{3}{*}{ SEM } & \multirow{2}{*}{\multicolumn{3}{|c|}{ Effect $^{2}$}} \\
\hline & \multicolumn{4}{|c|}{$0 \mathrm{~h}$} & \multicolumn{4}{|c|}{$12 \mathrm{~h}$} & \multicolumn{4}{|c|}{$24 \mathrm{~h}$} & & & & \\
\hline & CTR & LY & MY & HY & CTR & LY & MY & HY & CTR & LY & MY & HY & & $\mathrm{Y}$ & $\mathrm{T}$ & $\mathrm{Y} \times \mathrm{T}$ \\
\hline$\Sigma$ PUFA & 7.46 & 11.05 & 19.99 & 19.20 & 2.05 & 2.50 & 3.49 & 3.11 & 1.58 & 1.72 & 2.07 & 2.16 & 1.86 & 0.01 & $<0.01$ & 0.02 \\
\hline $18: 2$ cis -9, cis -12 & 6.70 & 9.96 & 18.16 & 17.28 & 1.64 & 2.06 & 2.93 & 2.63 & 1.19 & 1.29 & 1.64 & 1.71 & 1.72 & 0.01 & $<0.01$ & 0.02 \\
\hline$\Sigma$ MUFA cis & 15.61 & 16.58 & 18.46 & 20.79 & 8.39 & 8.51 & 9.10 & 9.85 & 6.29 & 6.42 & 5.21 & 6.72 & 0.60 & 0.01 & $<0.01$ & 0.01 \\
\hline $18: 1$ cis- 9 & 11.62 & 12.41 & 14.36 & 16.46 & 4.75 & 4.86 & 5.29 & 6.15 & 3.21 & 3.28 & 1.99 & 3.68 & 0.48 & $<0.01$ & $<0.01$ & 0.01 \\
\hline$\Sigma 18: 1$ trans & 4.06 & 4.54 & 3.90 & 3.35 & 8.99 & 9.15 & 9.30 & 8.12 & 7.92 & 7.89 & 8.17 & 7.13 & 0.14 & $<0.01$ & $<0.01$ & 0.06 \\
\hline $18: 1$ trans -10 & 0.44 & 0.42 & 0.36 & 0.33 & 0.68 & 0.59 & 0.64 & 0.60 & 0.64 & 0.57 & 0.58 & 0.61 & 0.03 & 0.01 & $<0.01$ & 0.20 \\
\hline 18:1 trans- 11 & 2.44 & 2.89 & 2.43 & 1.97 & 6.51 & 6.76 & 6.79 & 5.83 & 5.64 & 5.64 & 5.87 & 4.94 & 0.10 & $<0.01$ & $<0.01$ & 0.04 \\
\hline$\Sigma$ SFA & 69.76 & 64.70 & 54.25 & 53.05 & 77.45 & 76.31 & 71.59 & 74.82 & 77.63 & 78.41 & 77.40 & 78.08 & 2.96 & 0.02 & $<0.01$ & 0.09 \\
\hline 18:0 & 26.70 & 25.64 & 20.73 & 20.33 & 44.73 & 44.61 & 41.82 & 44.38 & 46.51 & 47.23 & 46.26 & 48.26 & 1.52 & 0.07 & $<0.01$ & 0.19 \\
\hline$\Sigma$ CLA & 0.07 & 0.14 & 0.18 & 0.29 & 0.01 & 0.00 & 0.05 & 0.00 & 0.00 & 0.00 & 0.02 & 0.00 & 0.03 & 0.07 & $<0.01$ & 0.05 \\
\hline cis-9,trans-11 CLA & 0.07 & 0.14 & 0.18 & 0.29 & 0.01 & 0.00 & 0.05 & 0.00 & 0.00 & 0.00 & 0.02 & 0.00 & 0.03 & 0.07 & $<0.01$ & 0.05 \\
\hline
\end{tabular}

${ }^{1} \mathrm{CTR}=$ no addition of I. orientalis; LY = addition of $I$. orientalis to achieve a projected concentration of $4.40 \mathrm{log}$ 10 $\mathrm{cfu} / \mathrm{mL}$ of culture medium; MY = addition of I. orientalis to achieve a projected concentration of $6.40 \log _{10} \mathrm{cfu} / \mathrm{mL} ; \mathrm{HY}=$ addition of $I$. orientalis to achieve a projected concentration of $8.40 \log _{10} \mathrm{cfu} / \mathrm{mL}$.

${ }^{2} \mathrm{Y}=$ yeast effect; $\mathrm{T}=$ incubation time effect; $\mathrm{Y} \times \mathrm{T}=$ interaction effect. 
and C18:1 cis-9 tended to decrease over time (Table 4). During the biohydrogenation process, C18:2 cis-9,cis-12 is converted to CLA and C18:1 trans intermediates. Cis-9, trans-11 CLA is one of the intermediates that is produced; however, no additional production of this CLA occurred during the in vitro incubations and the original amount at the moment of incubation was converted to C18:1 trans-11. As a result, increments in the production of $\mathrm{C} 18: 1$ trans-11 were reported after time 0 , and this trend clearly highlights the transitory nature of this biohydrogenation intermediate.

Trans-10,cis-12 CLA, another FA that can be formed during biohydrogenation of $\mathrm{C} 18: 2$ cis-9,cis-12 and that is the major FA inhibiting milk fat synthesis (Bauman et al., 2011), was not detected in our study. During biohydrogenation, this CLA is converted to C18:1 trans-10, and Table 4 shows that the proportion of C18:1 trans-10 was small. During biohydrogenation, CLA and C18:1 trans FA can be further hydrogenated and converted to stearic acid. Table 4 shows that after 12 and $24 \mathrm{~h}$ of incubation, the total amount of stearic acid increased; this result was expected because of extensive biohydrogenation. Choi et al. (2005) and Fuentes et al. (2009) reported that ruminal $\mathrm{pH}$ has a marked influence on ruminal biohydrogenation pathways. Choi et al. (2005) reported that production of trans-10,cis-12 CLA was much higher than that of cis-9,trans-11 CLA at $\mathrm{pH}$ 5.7, whereas Fuentes et al. (2009) reported that $\mathrm{pH} 5.6$ increased the flow of trans-10 18:1 and trans-10,cis-12 CLA. Because many of the bacteria that are able to synthesize trans-10, cis-12 CLA tend to predominate in low-pH environments, the high $\mathrm{pH}$ levels reported in our study may have minimized the formation of trans-10,cis-12 CLA and trans-10 18:1. Thus, further research is required to determine whether I. orientalis has a direct effect on biohydrogenation pathways toward the production of milk-fat-depressing CLA at $\mathrm{pH}$ values that are more similar to those of lactating cows or whether effects could be mediated through lower NDF-D. Based on the results of this study, no definitive conclusion can be made on the possibility that I. orientalis is responsible for reduced milk FA concentrations.

\section{CONCLUSIONS}

Our results suggest that a spoilage yeast commonly found in fermented silage may have the potential to directly alter fermentation in ruminal fluid if it is present in sufficiently high concentrations. Compared with the control treatment, the addition of high levels of $I$. orientalis resulted in a reduction in fiber digestibility and increased the concentrations of propionate and acetate in in vitro incubations. In vitro incubations with different levels of $I$. orientalis did not affect the major biohydrogenation pathways in the rumen but our in vitro conditions (relatively high $\mathrm{pH}$ ) may not have been conducive for this to occur. We evaluated only a single strain of yeast under in vitro conditions and thus our results should be considered with some caution. Future studies should investigate whether high numbers of mixed spoilage yeasts from silages (that naturally occur in vivo) affect in vivo ruminal metabolism. Future experiments might also be designed to study the potential of spoilage yeasts to alter biohydrogenation in the rumen under conditions (i.e., earlier time points, lower $\mathrm{pH}$, and ruminal fluid from donor animals fed high-concentrate diets) more favorable to alterations in biohydrogenation pathways.

\section{ACKNOWLEDGMENTS}

This study was partially funded by Elanco Animal Health Inc. (Greenfield, IN). The authors thank the staff of the Dairy Nutrition and Silage Fermentation Laboratory of the University of Delaware for their help with laboratory analysis. Appreciation is also extent to Courtney Preseault (Michigan State University, East Lansing) for assistance with FA analysis.

\section{REFERENCES}

Bauman, D. E., K. J. Harvatine, and A. L. Lock. 2011. Nutrigenomics, rumen-derived bioactive fatty acids, and the regulation of milk fat synthesis. Annu. Rev. Nutr. 31:299-319.

Belanche, A., M. Doreau, J. E. Edwards, J. M. Moorby, E. Pinloche, and C. J. Newbold. 2012. Shifts in the rumen microbiota due to the type of carbohydrate and level of protein ingested by dairy cattle are associated with changes in rumen fermentation. J. Nutr. 142:1684-1692.

Borreani, G., P. Dolci, E. Tabacco, and L. Cocolin. 2013. Aerobic deterioration stimulates outgrowth of spore-forming Paenibacillus in corn silage stored under oxygen-barrier or polyethylene films. J. Dairy Sci. 96:5206-5216.

Borreani, G., and E. Tabacco. 2014. Improving corn silage quality in the top layer of farm bunker silos through the use of a nextgeneration barrier film with high impermeability to oxygen. J. Dairy Sci. 97:2415-2426.

Choi, N. J., J. Y. Imm, S. J. Oh, B. C. Kim, H. J. Hwang, and Y. J. Kim. 2005. Effect of $\mathrm{pH}$ and oxygen on conjugated linoleic acid (CLA) production by mixed rumen bacteria from cows fed high concentrate and high forage diets. Anim. Feed Sci. Technol. 123-124:643-653.

Chung, Y. H., N. Walker, S. McGinn, and K. Beauchemin. 2011. Differing effects of 2 active dried yeast (Saccharomyces cerevisiae) strains on ruminal acidosis and methane production in nonlactating dairy cows. J. Dairy Sci. 94:2431-2439.

Desnoyers, M., S. Giger-Reverdin, G. Bertin, C. Duvaux-Ponter, and D. Sauvant. 2009. Meta-analysis of the influence of Saccharomyces cerevisiae supplementation on ruminal parameters and milk production of ruminants. J. Dairy Sci. 92:1620-1632.

Dolci, P., E. Tabacco, L. Cocolin, and G. Borreani. 2011. Microbial dynamics during aerobic exposure of corn silage stored under oxygen barrier or polyethylene films. Appl. Environ. Microbiol. 77:7499-7507.

Fuentes, M. C., S. Calsamiglia, P. W. Cardozo, and B. Vlaemink. 2009. Effect of $\mathrm{pH}$ and level of concentrate in the diet on the production of biohydrogenation intermediates in a dual-flow continuous culture. J. Dairy Sci. 92:4456-4466. 
Gerlach, K., K. Weiß, F. Roß, W. Buscher, and K.-H. Sudekum. 2013 Changes in maize silage fermentation products during aerobic deterioration and its impact on feed intake by goats. Agric. Food Sci. 22:168-181.

Goering, H. K., and P. J. Van Soest. 1970. Forage Fiber Analyses (Apparatus, Reagents, Procedures, and Some Applications). Agric. Handbook No. 379. ARS-USDA, Washington, DC.

Hoffman, P. C., and S. M. Ocker. 1997. Quantification of milk yield losses associated with feeding aerobically unstable high moisture corn. J. Dairy Sci. 80(E-Suppl. 1):234. (Abstr.)

Jenkins, T. C. 2010. Technical note: Common analytical errors yielding inaccurate results during analysis of fatty acids in feed and digesta samples. J. Dairy Sci. 93:1170-1174.

Jonsson, A., and G. Pahlow. 1984. Systematic classification and biochemical characterization of yeasts growing in grass silage inoculated with Lactobacillus cultures. Anim. Res. Develop. 20:7-22.

Kung, L., Jr., E. M. Kreck, and R. S. Tung. 1997. Effects of a live yeast culture and enzymes on in vitro ruminal fermentation and milk production of dairy cows. J. Dairy Sci. 80:2045-2051.

Lund, A. 1974. Yeasts and moulds in the bovine rumen. J. Gen. Microbiol. 81:453-462.

Maia, M. R. G., L. C. Chaudhary, L. Figueres, and R. J. Wallace. 2007. Metabolism of polyunsaturated fatty acids and their toxicity to the microflora of the rumen. Antonie Van Leeuwenhoek 91:303-314.

McDonald, P., A. R. Henderson, and S. J. E. Heron. 1991. The Biochemistry of Silage. 2nd ed. Chalcombe Publications, Marlow, UK.

Middelhoven, W. J. 1998. The yeast flora of maize silage. Food Technol. Biotechnol. 36:7-11.

Moon, N. J., and L. O. Ely. 1979. Identification and properties of yeasts associated with the aerobic deterioration of wheat and alfalfa silages. Mycopathologia 69:153-156.

Muck, R. E., and J. T. Dickerson. 1988. Storage temperature effects on proteolysis in alfalfa silage. Trans. ASAE 31:1005-1009.
NRC. 2001. Nutrient Requirements of Dairy Cattle. 7th rev. ed. Natl Acad. Sci., Washington, DC.

Santos, M. C., C. Golt, R. D. Joerger, G. D. Mechor, and L. Kung Jr. 2011. Identification and characterization of spoilage yeasts from high moisture corn and corn silages. J. Dairy Sci. 94(E-Suppl. 1):550. (Abstr.)

SAS Institute. 1999. SAS User's Guide: Statistics. SAS Inst. Inc., Cary, NC

Timke, M., N. Q. Wang-Lieu, K. Altendorf, and A. Lipski. 2008. Identity, beer spoiling and biofilm forming potential of yeasts from beer bottling plant associated biofilms. Antonie van Leeuwenhoek 93:151-161.

Tripathi, M. K., S. Karim, O. Chaturvedi, and D. Verma. 2008. Effect of different liquid cultures of live yeast strains on performance, ruminal fermentation and microbial protein synthesis in lambs. J. Anim. Physiol. Anim. Nutr. (Berl.) 92:631-639.

Van Soest, P. J., J. B. Robertson, and B. A. Lewis. 1991. Methods for dietary fiber, neutral detergent fiber, and nonstarch polysaccharides in relation to animal nutrition. J. Dairy Sci. 74:3583-3597.

Vissers, M. M. M., F. Driehuis, M. C. Te Giffel, P. De Jong, and J. M. G. Lankveld. 2007. Concentration of butyric acid bacteria spores in silage and relationships with aerobic deterioration. J. Dairy Sci. 90:928-936.

Ward, R. 2011. Analyzing silage crops for quality: What is most important? Pages 46-65 in Proc. Western Alfalfa and Forage Conference. Univ. California, Davis.

Weimer, P. J. 1996. Why don`t ruminal bacteria digest cellulose faster? J. Dairy Sci. 79:1496-1502.

Whitlock, L. A., T. J. Wistuba, M. K. Seifers, R. V. Pope, and K. K. Bolsen. 2000. Effect of level of surface-spoiled silage on the nutritive value of corn silage diets. J. Dairy Sci. 83(E-Suppl. 1):110. (Abstr.) 